\title{
Evaluation of Binding Affinity of Protein-Mutant DNA Complexes in Solution by Laser Spray Mass Spectrometry
}

\author{
Xiangguo Shi, Yoshifumi Nishimura, and Satoko Akashi \\ International Graduate School of Arts and Sciences, Yokohama City University, Yokohama, Japan
}

\author{
Atsushi Takamizawa and Kenzo Hiraoka \\ Clean Energy Research Center, University of Yamanashi, Kofu, Japan
}

\begin{abstract}
We have applied laser spray mass spectrometry developed by Hiraoka et al. to investigate the binding affinity of protein-mutant DNA complexes. The results were compared with our previous data of collision-induced dissociation (CID) experiments using electrospray ionization mass spectrometry (ESI-MS). Systematic experiments were carried out on the complexes of the c-Myb DNA binding domain (c-Myb DBD) bound to eight kinds of 16- or 22-mer point mutant double-stranded DNA (dsDNA), whose solution $K_{d}$ values are different in the range from $10^{-9} \mathrm{M}$ to $10^{-7} \mathrm{M}$. The dissociation curve as a function of laser power was plotted for each complex, and the laser power where $50 \%$ of complex was dissociated $\left(E_{50 \%}\right)$ in population was obtained. The correlation coefficient between $\mathrm{E}_{50 \%}$ and the relative binding free-energy change $(\Delta \Delta G)$ of each complex formation in solutions was 0.9808 , which is much better than the coefficient obtained by the previous ESI-CID experiments that was 0.859. In addition, complexes of the c-Myb DBD with five other mutant dsDNA were also examined to confirm that laser spray can be used to estimate the $K_{d}$ values of a DNA-protein complex in solutions if an appropriate calibration curve is available. In the process of laser spray, dissociations of these noncovalent complexes occur in solutions, but not in the gas phase. This differs greatly from ESI-CID. Laser spray mass spectrometry has been found to be better than ESI-CID in evaluating binding affinity of a protein to various mutant DNA. (J Am Soc Mass Spectrom 2006, 17, 611-620) (C) 2006 American Society for Mass Spectrometry
\end{abstract}

$\mathrm{E}$ lectrospray ionization mass spectrometry (ESIMS) has been successfully applied to detect the protonated molecules of noncovalent biomolecular complexes that are involved in various important biological events [1-8]. Although mass spectrometry cannot provide structural information of a biological complex at an atomic level, it can rapidly offer information on the binding stoichiometry, specificity, and stability of the complex with a small amount of the sample. In addition, dissociation of the complex can also be achieved by changing the mass spectrometric parameters. We have previously applied ESI-MS to examine the binding affinity of a protein to various double-stranded DNA (dsDNA) oligomers [9] by using a minimal DNA-binding domain (DBD) of a transcription factor c-Myb [10].

The c-Myb DBD, $13 \mathrm{kDa}$, specifically recognizes

Published online February 20, 2006

Address reprint requests to Dr. S. Akashi, International Graduate School of Arts and Sciences, Yokohama City University, 1-7-29 Suehiro-cho, Tsurumiku, Yokohama, Kanagawa 230-0045, Japan. E-mail: akashi@tsurumi. yokohama-cu.ac.jp, or to Dr. K. Hiraoka, Clean Energy Research Center, University of Yamanashi, Takeda-4, Kofu 400-8511, Japan. E-mail: hiraoka@ab11.yamanashi.ac.jp.
dsDNA with the consensus sequence of AACNG ( $\mathrm{N}$ denotes $\mathrm{A}$ or $\mathrm{T}$ or $\mathrm{G}$ or $\mathrm{C}$ ) [11-13]. We have carried out systematic investigation on the gas-phase stability of the complexes of the c-Myb DBD bound to seven 22-mer dsDNA oligomers. The dsDNA are single-point mutants and the complexes of the c-Myb DBD with dsDNA mutants have different solution $K_{d}$ values in a wide range of $6.3 \times 10^{-7} \mathrm{M}$ to $2.8 \times 10^{-9} \mathrm{M}$. Multiply protonated molecules of the complexes were generated by ESI-MS, and successively subjected to collision induced dissociation (CID) in the first vacuum region [9]. A dissociation curve as a function of cone voltage was plotted, and the cone voltage where $50 \%$ of the population of the complex was dissociated $\left(\mathrm{V}_{50 \%}\right)$ was calculated for each protein-DNA complex. A positive correlation was recognized between the stability of the gas-phase molecular ion of the protein-DNA complex and the relative binding free-energy change $(\Delta \Delta G)$ of the complex formation in solution. However, some problems still existed that had to be resolved for rigorous quantification of the binding affinity of a protein to dsDNA. When the cone voltage was increased over 70 $\mathrm{V}$ in ESI-CID experiments, significant degradation of DNA was recognized $[8,9]$ in addition to the dissocia- 
tion of the complex. This indicates that collision energy was consumed not only for dissociation of the proteinDNA complex, but also for cleavage of weak covalent bonds in DNA. To evaluate the binding affinity of the protein-DNA complex more accurately by mass spectrometry, such degradation of DNA should be avoided during the dissociation process. If the degradation of DNA during the dissociation of the complex can be avoided, a more accurate estimation of the binding affinity of the protein-DNA complex can be achieved by mass spectrometry experiments.

Laser spray, which was developed by Hiraoka et al. [14-19], is a promising tool for the characterization of biomolecules. The basic features of this method are summarized as follows: (1) laser spray generally gives stronger ion signals than electrospray; (2) thermal degradation of covalent bonds is not observed for thermally labile compounds; (3) laser spray is more suitable for the detection of less surface-active ions than electrospray; (4) laser spray is most suitable for aqueous solutions, which are not easy to handle by electrospray; and (5) laser spray enables selective dissociation of noncovalent bonds. These advantages originate from the fact that liquid water has an absorption coefficient of $832 \mathrm{~cm}^{-1}$ with $10.6 \mu \mathrm{m}$ infrared light and laser spray can generate plumes composed of finer charged liquid droplets than electrospray [14].

Laser spray enables complete dissociation of the complex without any fragmentation of DNA moiety in solution by prompt heating of the sample solution on the tip of a stainless-steel capillary [19]. Here, we have applied this newly-developed laser spray to solve the problems observed in ESI-CID experiments. Since electrostatic interactions are strengthened in vacuum [20], the binding affinity of some complexes with different binding modes (i.e., electrostatic interactions versus hydrophobic interactions) may not be accurately evaluated by ESI-CID experiments. Events of laser spray occur in the solution phase, but not in the gas phase, and thus laser spray is expected to reflect faithfully the biophysical characteristics of the complexes in solution, such as binding affinity. Consequently, this technique might also be promising for the evaluation of the binding affinity of other complexes, such as proteinprotein, protein-ligand, and DNA-drug. Laser-induced liquid beam ionization/desorption mass spectrometry (LILBID-MS) is another method that utilizes laser irradiation for the analysis of noncovalent complexes [21, 22]. This method can allow detection of the dissociation of noncovalent complexes, but it suffers from the disadvantage that most of the aqueous sample is wasted in a cold trap [21, 22]. In contrast, noncovalent bonds of proteins and DNA are readily and selectively cleaved by laser spray with a power of less than $1.6 \mathrm{~W}$ [19], with much higher throughput than LILBID-MS.

Laser spray generates finer droplets and sensitivity increases about ten times higher than ESI. The convenience of laser spray is an advantage because thermal heating is completed instantaneously right after the laser irradiation. To evaluate the binding affinity of the biomolecular complexes, some solution-phase methods based on MS detection have been established (reviewed in [2]). Thermal denaturation of the sample is one of the promising methods [6, 23-26]. For plotting the melting curves by controlling the probe temperature, it is important to regulate the temperature of the spray capillary accurately. Since it takes time for the equilibration of the capillary temperature, high-throughput analysis is not easy to perform. As for the titration method [27, 28], samples should be prepared at various concentrations or volume. The competition method is also promising for the analysis of the binding affinity of noncovalent complexes $[29,30]$. It is not practical, however, for the evaluation of the binding affinity of proteinmutant DNA interactions because the mass increase caused by adduct of monovalent cations with doublestranded DNA makes it difficult to differentiate single nucleotide substitution within a sequence of DNA with more than 10-base pairs. Compared with these methods, laser spray is rapid and convenient for the evaluation of the binding affinity of the protein-mutant DNA.

Here, we have examined laser spray to find out if it can be a good method for evaluation of the binding affinity of noncovalent complexes between the c-Myb DBD and 16- or 22-mer singly-mutated dsDNA with different solution $K_{d}$ values. We have found that there is a correlation between the laser power required for the dissociation of the complex and the solution $K_{d}$ values. It has been demonstrated that laser spray can characterize the binding affinity of protein-mutant DNA complexes more conveniently and accurately than ESI-CID.

\section{Experimental}

\section{Materials}

All reagents used were analytical grade. Water was purchased from Merck (Darmstadt, Germany), and ammonium acetate (ReagentPlus, 99.99+\%) was from Aldrich (Milwaukee, WI). The c-Myb DBD (R2R3) with the sequence of MELIKGPWTKEEDQRVIKLQKYGPKRWSVI AKHLKGRIGKQCRERWHNHLNPE(R2)VKKTSWTEEE DRIIYQAHKRLGNRWAEIAKLLPGRTDNAIKNHWNS TMRRKV(R3) was prepared as previously described [31, 32]. Briefly, the c-Myb DBD was expressed in E. coli BL21(DE3) using a T7 expression system, grown in SB medium, and purified by successive column chromatography using phosphocellulose (P11, Whatman, Brentford, UK), carboxymethyl-cellulose (CM52, Whatman), phenylsepharose (Amersham, Piscataway, NJ), and Superdex 75 (Amersham) columns. The stock solution of the c-Myb DBD was prepared in $100 \mathrm{mM}$ potassium phosphate $(\mathrm{pH}$ 6.7) with $10 \mathrm{mM}$ dithiothreitol and $1 \mathrm{mM}$ sodium azide by ultrafiltration using Ultrafree (MW cut off 5000, Millipore, Billerica, MA) and stored at $4{ }^{\circ} \mathrm{C}$ before use. The concentration of the c-Myb DBD in stock solution was estimated 
from UV absorbance at $280 \mathrm{~nm}$ using the $\varepsilon_{280}=36.2 \times 10^{3}$ $\mathrm{M}^{-1} \mathrm{~cm}^{-1}$ for the c-Myb DBD. Chemically synthesized 16and 22-mer single-stranded DNA (ssDNA) oligomers were purchased from Bex Co. Ltd. (Tokyo, Japan). Each ssDNA was dissolved in $1 \mathrm{M}$ ammonium acetate ( $\mathrm{pH}$ 6.7), and its concentration was estimated from UV absorbance at $260 \mathrm{~nm}$. Two complementary ssDNA molecules were annealed by cooling slowly from $90^{\circ} \mathrm{C}$ to room temperature in $1 \mathrm{M}$ ammonium acetate $(\mathrm{pH}$ 6.7), resulting in 0.5 $\mathrm{mM}$ dsDNA stock solution. Annealed dsDNA stock solution was stored at $4{ }^{\circ} \mathrm{C}$ before use.

\section{Preparation of Protein-DNA Complex}

A $6.9 \mu \mathrm{L}$ aliquot of c-Myb DBD stock solution $(0.72$ $\mathrm{mM}$ ) was diluted with $340 \mu \mathrm{L}$ of $10 \mathrm{mM}$ ammonium acetate ( $\mathrm{pH}$ 6.7), and then $10 \mu \mathrm{L}$ of dsDNA stock solution $(0.5 \mathrm{mM})$ was added and mixed in a molecular ratio of 1:1. The sample solution was ultrafiltrated against $10 \mathrm{mM}$ ammonium acetate $(\mathrm{pH}$ 6.7) using Millipore Ultrafree (MW cut off 10,000), and a $100 \mu \mathrm{M}$ solution of protein-DNA complex was prepared. The binding activity of the c-Myb DBD to some dsDNA oligomers was also confirmed by gel-mobility assay.

\section{Mass Spectrometry}

A stainless-steel capillary (i.d. $0.1 \mathrm{~mm}$, o.d. $0.2 \mathrm{~mm}$ ) parallel to the interface plate was supplied with a sample solution by using a syringe pump (Harvard Apparatus, type 11 Plus, Holliston, MA). Nebulizer gas $\left(\mathrm{N}_{2}, 500 \mathrm{ml} / \mathrm{min}\right)$ effusing from the concentric stainlesssteel tube (i.d. $0.7 \mathrm{~mm}$ ) reduced the angular divergence of the plume and entrained the mist and gas in a confined gas stream passing towards the sampling orifice. A Synrad (Bothel, WA) model FSV20SFB maximum $20 \mathrm{~W}$ infrared laser $(10.6 \mu \mathrm{m})$ was used for the laser spray experiments. Electrospray mass spectra, without laser irradiation, were obtained before the laser spray by applying a high voltage $(2800 \mathrm{~V})$ to the capillary. The tip of the stainless-steel capillary was then irradiated axially from the opposite side of the capillary by an infrared laser beam focused to about 0.3 $\mathrm{mm}$. A schematic representation of laser spray ion source is indicated in Figure 1. The gaseous ions formed from the aqueous sample solution at atmospheric pressure were sampled through a $400 \mu \mathrm{m}$ diameter orifice into the vacuum system, and mass analysis was carried out by an orthogonal time-of-flight mass spectrometer (AccuTOF, JEOL, Musashino, Tokyo, Japan) over the range of $\mathrm{m} / \mathrm{z} 600$ to 4000 . Calibration of the instrument was carried out using $(\mathrm{CsI})_{\mathrm{n}} \mathrm{Cs}^{+}$. The flow-rate of the sample solution was set to $5 \mu \mathrm{l} / \mathrm{min}$. Electrospray and laser spray experiments were performed in the open air by removing the commercial desolvation chamber. The ion signals of electrospray obtained under the present experimental conditions decreased to about half of those obtained by using the desolvation chamber. The temperature of the ion sampling orifice was kept at $50{ }^{\circ} \mathrm{C}$. Ions were collimated

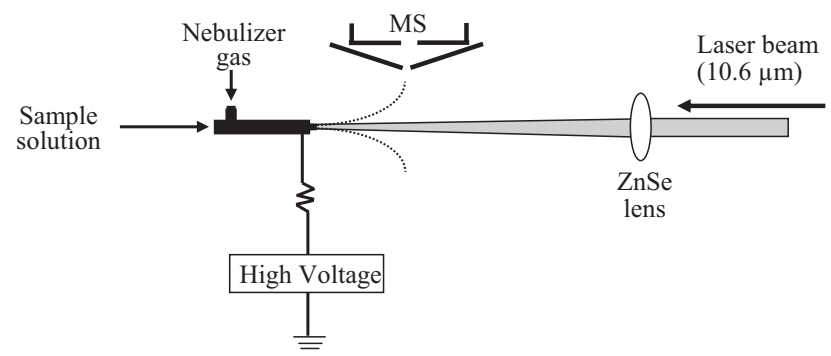

Figure 1. A schematic representation of laser spray ion source. An aqueous sample solution flowing out from the tip of the stainless steel capillary is irradiated by a $10.6 \mu \mathrm{m}$ infrared laser. Before laser irradiation, a high electric field is applied to the stainless steel capillary. Nebulizer gas is used to help the ionization process [14].

using a lens voltage of $17 \mathrm{~V}$, an orifice 1 voltage of $50 \mathrm{~V}$ and an orifice 2 voltage of $5 \mathrm{~V}$. Mass Center version 1.1.5 software (JEOL, Musashino, Tokyo, Japan) was used for data processing and peak integration.

The sample solution of $100 \mu \mathrm{M}$ c-Myb DBD or 100 $\mu \mathrm{M}$ c-Myb DBD-dsDNA complex in $10 \mathrm{mM}$ ammonium acetate solution ( $\mathrm{pH}$ 6.7) was prepared by extensive buffer exchange using Millipore Ultrafree before mass measurement. This solution was diluted with an appropriate concentration of ammonium acetate (10-100 $\mathrm{mM}$ ) to dilute the concentration of the analyte to $20 \mu \mathrm{M}$. The formation of each complex was identified by ESI-MS (laser off) before the acquisition of laser spray mass spectra at laser-irradiation powers of $0.6,0.8,1.0$, $1.2,1.4$, and 1.6 W. Each experiment was repeated three times. The percentage of complex was obtained by calculating the ratio of the peak area of the complex to the total peak area of molecular ions of the protein and complex. The percentage of complex was plotted as a function of laser power and the dissociation curve was obtained for each c-Myb DBD-mutant dsDNA complex. The correlation between the laser power of the $50 \%$ complex content $\left(\mathrm{E}_{50 \%}\right)$ and the solution-phase $\Delta \Delta G(\mathrm{kcal} / \mathrm{mol})$, which had been determined by filter-binding assay [13], was investigated for each protein-dsDNA complex.

\section{Results and Discussion}

\section{Observation of c-Myb DBD-dsDNA Complex}

The binding affinity of the c-Myb DBD to its specific dsDNA, m22 [22 mer, 5' CAC CCT AAC TGA CAC ACA TTC T $3^{\prime}(+)$ (MW 6583.3) and its complementary strand (-) (MW 6885.6)] is the highest in the complexes as listed in Table 1. The dissociation constant in solution [100 $\mathrm{mM}$ potassium phosphate buffer ( $\mathrm{pH} 7.5)$ with 20 $\mathrm{mM} \mathrm{KCl}, 0.1 \mathrm{mM}$ EDTA, $500 \mu \mathrm{g} / \mathrm{mL}$ of bovine serum albumin, 5\% (vol/vol) glycerol, and $10 \mathrm{mM}$ dithiothreitol] of this complex had been determined as $K_{d}=2.8 \times$ $10^{-9} \mathrm{M}$ by filter-binding assay [13]. We used this complex to optimize analytical parameters of the mass spectrometer and salt concentration of the sample buffer for mass analysis of the c-Myb DBD-dsDNA 
Table 1. Sequences of $16,22-$ mer dsDNA and $\Delta \Delta G[\mathrm{kcal} / \mathrm{mol}]$ and $K_{d}[\mathrm{M}]$ of the corresponding complexes with c-Myb DBD determined by previous filter-binding assay [13]

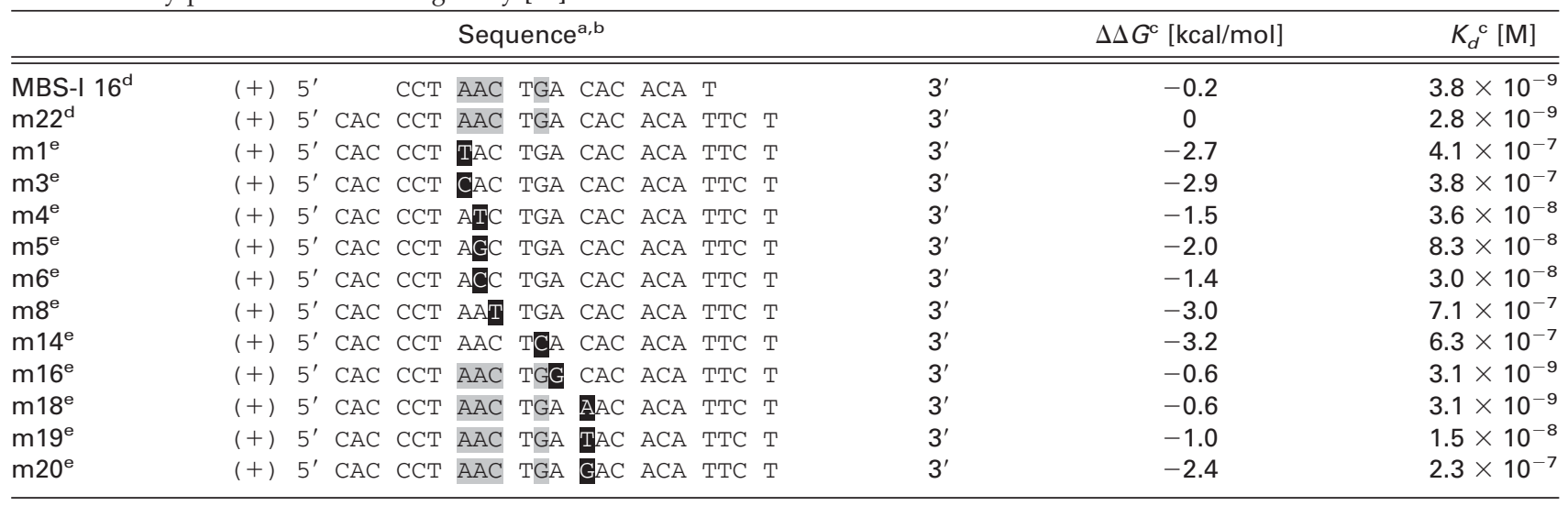

a Gray boxes indicate the consensus sequence which the c-Myb DBD specifically recognizes.

bBlack boxes with white letters indicate the mutated positions in mutant dsDNA.

${ }^{\mathrm{c}}$ Relative binding free energy change associated with the base-pair substitution can be calculated by the following equation: $\Delta \Delta G=\Delta G_{m}-\Delta G_{w t}$ $=-\mathrm{RT} \ln \left[K_{d}(\mathrm{~m}) / K_{d}(\mathrm{wt})\right] ; \Delta G_{m}: \Delta G$ for mutant; $\Delta G_{w t}: \Delta G$ for wild type $(\mathrm{m} 22) ; K_{d}(\mathrm{~m}): K_{d}$ for mutant; $K_{d}(\mathrm{wt}): K_{d}$ for wild type (m22); $K_{d}$ for each complex was determined by filter-binding assay.

dSequences of MBS-I 16 and $\mathrm{m} 22$ are wild-type.

${ }^{\mathrm{e}} \mathrm{m} 1, \mathrm{~m} 3, \mathrm{~m} 4, \mathrm{~m} 5, \mathrm{~m} 6, \mathrm{~m} 8, \mathrm{~m} 14, \mathrm{~m} 16, \mathrm{~m} 18, \mathrm{~m} 19$, and $\mathrm{m} 20$ are single point mutants of $\mathrm{m} 22$.

complex. The binding affinity of the c-Myb DBD to dsDNA-m22 was confirmed by gel-mobility assay (data not shown) and ESI mass spectrometry, which was consistent with our previous report [9].

The ion source used in the present study is the same as the conventional ESI source except that the commercial desolvation chamber is removed for the consecutive laser spray experiments in the open air. Figure 2 shows the ESI (laser off) mass spectra of the complex of c-Myb DBD with m22 (upper panel) and free c-Myb DBD (lower panel) prepared in $50 \mathrm{mM}$ ammonium acetate ( $\mathrm{pH}$ 6.7). The ESI mass spectrum of the complex showed the peaks of 1:1 complex of the protein-dsDNA in which a few weak peaks of free c-Myb DBD were also observed with low intensity. The peaks of the complex

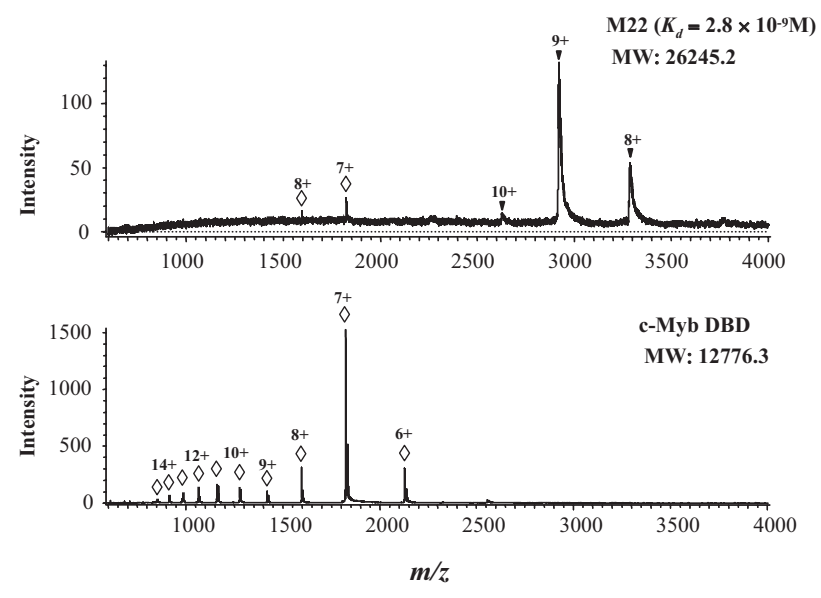

Figure 2. ESI mass spectra (laser off) of free c-Myb DBD (lower panel) and a complex of the c-Myb DBD with dsDNA-m22 (upper panel). Multiply charged peaks of the c-Myb DBD and proteindsDNA complex are marked with open diamond and inverted filled triangle, respectively. were a little broadened due to the association of dsDNA, which is apt to retain adduct ions such as $\mathrm{Na}^{+}$.

\section{Effect of Laser Spray on the Conformational Change of $c-M y b D B D$ and Complex}

Bimodal charge distribution of the multiply charged peaks of free c-Myb DBD (6+ to 9+, and 9+ to $18+$ ) was observed in ESI mass spectra (laser off), as shown in Figures 2 and 3. The most intense peak of the free protein was $[\mathrm{M}+7 \mathrm{H}]^{7+}$. The relative intensity of the protein peaks with $9+$ to $18+$ charges increased in laser spray mass spectra in comparison with the corresponding peaks in the ESI mass spectrum.

The c-Myb DBD (R2R3) is composed of two $\alpha$-helical fragments R2 and R3. Circular dichroism (CD) and differential scanning calorimetry (DSC) showed that the $\mathrm{R} 2$ region in the c-Myb DBD is thermally unstable when compared to the R3 region [33]. So the charge distribution of protein peaks in the mass region of $\mathrm{m} / \mathrm{z} 1400$ to 2200 may represent the native state of the c-Myb DBD, whereas the charge distribution of peaks in $\mathrm{m} / \mathrm{z} 600$ to 1500 may represent a partly denatured conformation of the c-Myb DBD. The relative peak intensity of these denatured species was increased in relation to the increase in laser power, as described above.

In contrast, the charge distribution of the $\mathrm{c}-\mathrm{Myb}$ DBD-dsDNA complex was not largely changed by laser irradiation. This indicates that the binding of dsDNA to the protein increases the stability of protein. This is consistent with the data from DSC [33], which showed a larger enthalpy change for the denaturation of the c-Myb DBD in the presence of DNA than that in the absence of DNA. More extensive denaturation of the c-Myb DBD might be accomplished by the laser irradiation with stronger laser 

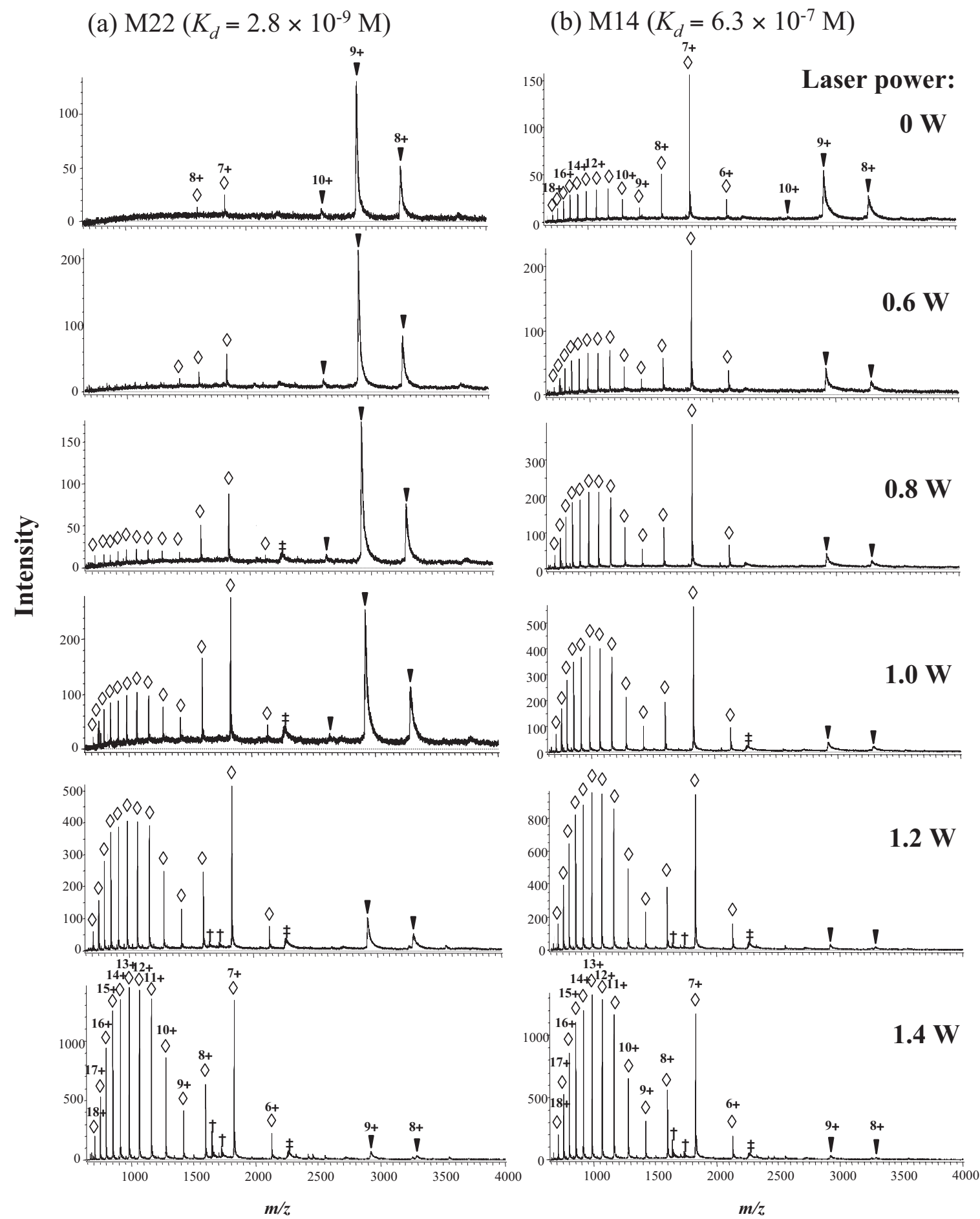

Figure 3. ESI and laser spray mass spectra of complexes of (a) the c-Myb DBD with $\mathrm{m} 22$ and (b) the c-Myb DBD with m14 in $50 \mathrm{mM}$ ammonium acetate obtained at laser power of $0,0.6,0.8,1.0,1.2$, and $1.4 \mathrm{~W}$. Multiply charged peaks of the c-Myb DBD and protein-dsDNA complex are marked with open diamond and filled inverted triangle, respectively. The single and double dagger symbols represent $4+$ charged peaks of two ssDNA and $6+$ charged peaks of dsDNA, respectively.

power than $1.6 \mathrm{~W}$. Irradiation with higher laser power than $1.6 \mathrm{~W}$, however, might deteriorate the tip of the stainless-steel capillary under the present experimental conditions (i.e., sample flow rate of 5 $\mu \mathrm{l} / \mathrm{min}$ and the nebulizer gas of about $500 \mathrm{~mL} / \mathrm{min}$ ).
Therefore, experiments in laser irradiation were conducted at different laser power levels $(0.6,0.8,1.0,1.2$, 1.4 , and 1.6 W). As shown in Figure 3, the laser power level of $1.6 \mathrm{~W}$ was found to be strong enough to denature the c-Myb DBD in solution. Laser spray 
appears to be ideal for probing the conformational changes and thermodynamic characteristics of proteins and their noncovalent complexes [34].

\section{Effect of Laser Spray on the Sensitivity and Complex Dissociation}

Rapid evaporation caused by the laser irradiation brings about the enrichment of the analyte near to the surface of the liquid droplet, and this is likely a major reason for the rapid increase in the intensity of the peaks in laser spray mass spectra. Laser spray mass spectra of two complexes M22 and M14, whose $K_{d}$ values had been determined as $2.8 \times 10^{-9} \mathrm{M}$ and $6.3 \times$ $10^{-7} \mathrm{M}$, respectively, are shown as typical examples in Figure 3. Our preliminary experiments have indicated that $0.4 \mathrm{~W}$ of the laser power had only slightly facilitated the concentration of the analyte and the dissociation of the complexes. Hence, most laser spray experiments were carried out at the laser power of 0.6 to 1.4 $\mathrm{W}$. When the laser power was set to between 0.6 and 1.0 $\mathrm{W}$, the laser energy transferred into the sample solution could increase the intensity of the analyte. Dissociation of weakly-bound complexes, such as M14, could also be analyzed within this range of the laser power (Figure $3 b)$. Furthermore, the intensity of the c-Myb DBD peaks generated by the dissociation of the complex was dramatically improved with the increase of the laser power to higher than $1.0 \mathrm{~W}$, and multiply protonated molecules of the dissociated dsDNA and ssDNA also appeared in the mass spectra (Figure 3). With the increase of the laser power up to $1.4 \mathrm{~W}$, peaks of protonated molecules of the c-Myb DBD-dsDNA complex were barely recognized whereas the intensity of multiply protonated molecules of the dissociated c-Myb DBD increased by a factor of about nine. We also found that laser spray had little effect on improving the sensitivity of protonated molecules of DNA in the positive ion mode, although the intensity of protonated molecules of the protein was greatly improved.

Singly mutated oligonucleotides composed of 22base pairs were used in the present study for the investigation of the binding affinity to the c-Myb DBD. Since a single mutation among 22-base pairs is expected to only slightly affect ionization and detection efficiency of the protein-DNA complex, signal intensity of each complex would be almost the same if an equal amount of the complex exists in the sample solution. Upon laser irradiation, the complex is dissociated into free protein and oligonucleotides. It is preferable to observe the absolute change in the intensity of the complex alone by laser irradiation, but it is impossible because of concomitant dissociation of the complex in the solution by laser irradiation. Higher laser power generates a smaller amount of the complex, which makes it impossible to determine the absolute increase in intensity of the complex by laser irradiation. In addition, relative intensity of the complex should have been reduced by the dissociated free protein, whose absolute intensity should be much higher than that of the complex.

Figure 3 indicates that prompt heating of the sample solution by a laser is significantly more effective for selective dissociation of noncovalent bonds. Neither dissociated ions generated by the loss of neutral bases from the intact duplex DNA ions nor fragments from ssDNA were observed in the laser spray mass spectra. In contrast, fragmentation and degradation of DNA moiety were recognized to some extent in our previous ESI-CID experiments, as shown in Figure 4, which resulted in a less accurate evaluation of the binding affinity of protein-DNA complexes [9]. These results suggest that the dissociation mechanism of laser spray is fundamentally different from that of ESI-CID. Dissociation in laser spray is a result that originates from the solution phase while that in ESI-CID is from the gas phase. No fragmentation of DNA moiety in laser spray is advantageous to the evaluation of binding affinity of protein-dsDNA complexes.

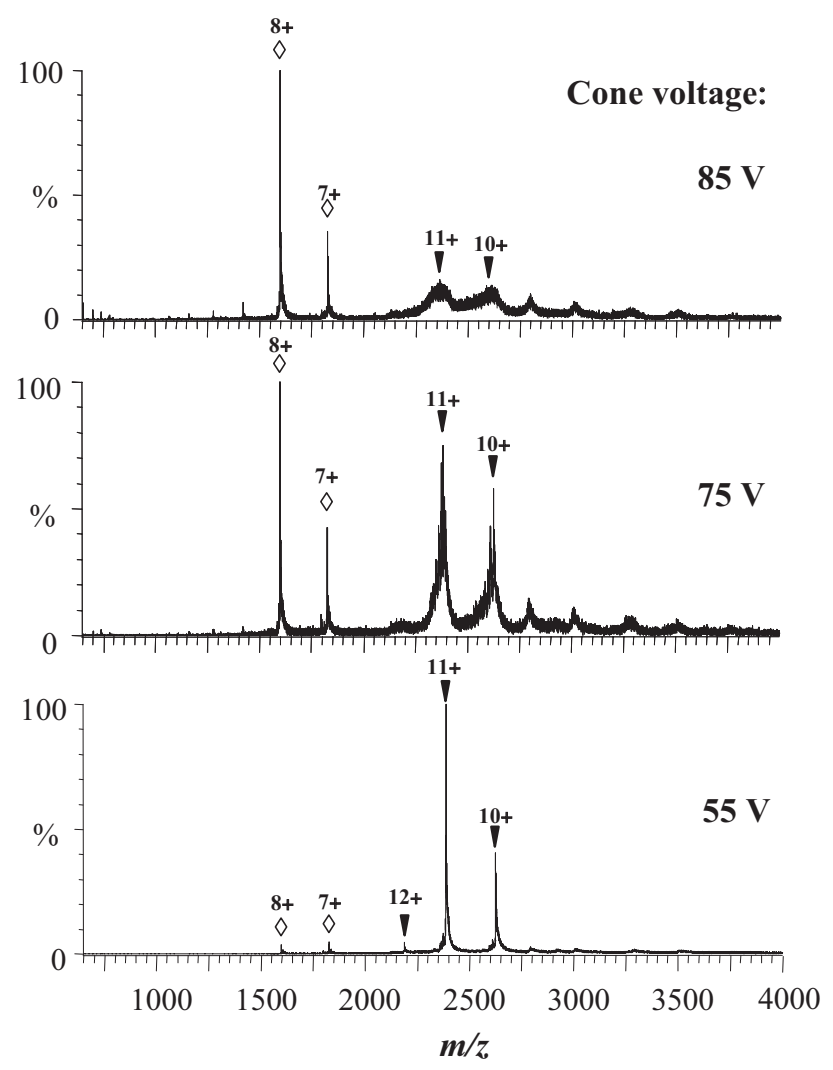

Figure 4. ESI mass spectra of complexes of the c-Myb DBD with $\mathrm{m} 22$. Samples were prepared with $500 \mathrm{mM}$ ammonium acetate. Dissociation of the complexes is recognized as increasing in the voltage $(50-100 \mathrm{~V})$ of the sample cone in the ion source [9]. Multiply charged peaks of the c-Myb DBD and protein-dsDNA complex are marked with open diamond and filled inverted diamond, respectively. 


\section{Effect of Salt Concentration on Complex Dissociation by Laser Spray}

In our previous ESI-CID experiments, complexes prepared in less than $50 \mathrm{mM}$ ammonium acetate did not allow us to observe the dissociated free c-Myb DBD [9]. Protonated molecules of the complex in the buffer of less than $50 \mathrm{mM}$ ammonium acetate only showed extreme peak-broadening when the cone voltage was increased up to $100 \mathrm{~V}$ in ESI-CID experiments, and no protonated molecules of the free c-Myb DBD appeared in the spectrum. To dissociate the protein-DNA complex, a high salt concentration $(500 \mathrm{mM}$ ammonium acetate) was required for the sample preparation to weaken electrostatic interactions between the protein and DNA (Figure 4).

We found that laser spray, in contrast to ESI, prefers a lower salt concentration for the dissociation of the complex. Laser spray can dissociate all the proteinDNA complexes prepared in $10 \mathrm{mM}$ ammonium acetate, and no peak-broadening of the protonated molecules of the complex was recognized with the increase of the laser power up to $1.4 \mathrm{~W}$. Higher laser power was required to completely dissociate the protein-DNA complexes when the sample was prepared in $50 \mathrm{mM}$ ammonium acetate than when prepared in $10 \mathrm{mM}$ ammonium acetate, as shown in Figure 5. If the concentration of ammonium acetate was higher than $100 \mathrm{mM}$, it was difficult to observe dissociation of the complexes (data not shown). It has to also be pointed out that the buffer of more than $10 \mathrm{mM}$ ammonium acetate reduces the absolute intensity of the molecular ions of the protein and complexes in laser spray mass spectra, as previously reported [35]. The absolute intensities of protein signals are about ten times higher than those in ESI mass spectra when the sample is prepared in $10 \mathrm{mM}$ ammonium acetate. In the case of $50 \mathrm{mM}$ ammonium acetate, the absolute intensities of protein signals in laser spray mass spectra are almost equal to those in ESI mass spectra. This indicates that the effect of laser spray is significant at a lower concentration of ammonium acetate, but no considerable advantage in sensitivity is found for laser spray when the sample is dissolved in $>50 \mathrm{mM}$ ammonium acetate. Additives to the water, even volatile salts, largely affect the results of laser spray, for example, in cleavages of noncovalent bonds and sensitivity. The matrix is critical to the results because laser spray may be regarded as electric fieldassisted matrix-assisted laser desorption/ionization (MALDI) [14]. High concentration of ammonium acetate may cause a decrease in the absorption of $10.6 \mu \mathrm{m}$ laser, resulting in lowering the efficiency of thermal transfer upon laser irradiation. This may have led to lowering the efficiency in the dissociation of the complex. Further investigation on the mechanism of energytransfer to the liquid droplets is now in progress.

In general, binding between a protein and DNA is strengthened in a lower concentration of salt. As shown in Figure 5, however, the ratio of the complex in $50 \mathrm{mM}$ ammonium acetate was calculated as higher than that in $10 \mathrm{mM}$ ammonium acetate when the laser was off, i.e., in ESI mass spectra. This might be caused by unique characters of c-Myb DBD. The ESI mass spectrum of free c-Myb DBD indicates that some parts of the population of the protein prepared in $50 \mathrm{mM}$ ammonium acetate were partially denatured under the measurement conditions of ESIMS and molecular ions with from $9+$ to $15+$ were observed in addition to less charged ions, as shown in Figure 2. In contrast, in our previous experiment, the ESI-CID spectrum of the complex that was prepared in $500 \mathrm{mM}$ ammonium acetate gave only less charged species for dissociated protein by increasing the cone voltage, as in Figure 4. Charge distribution of the free c-Myb DBD in Figure 4 is clearly different from that in Figure 2. The relative intensity of the peaks with higher charges $(9+$ to $15+)$ was higher in the ESI mass spectrum of c-Myb DBD in $10 \mathrm{mM}$ ammonium acetate compared with those in $50 \mathrm{mM}$ ammonium acetate (data not shown). These results may (a)

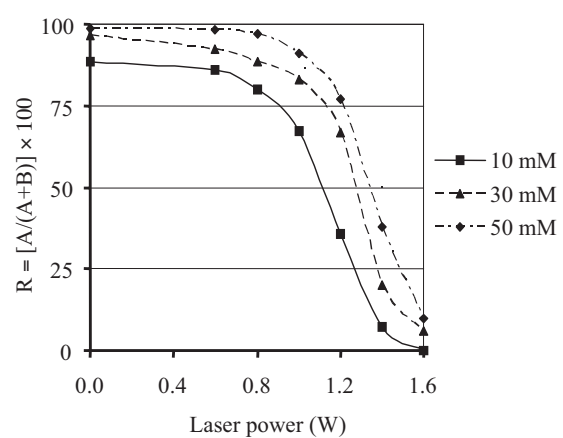

(b)

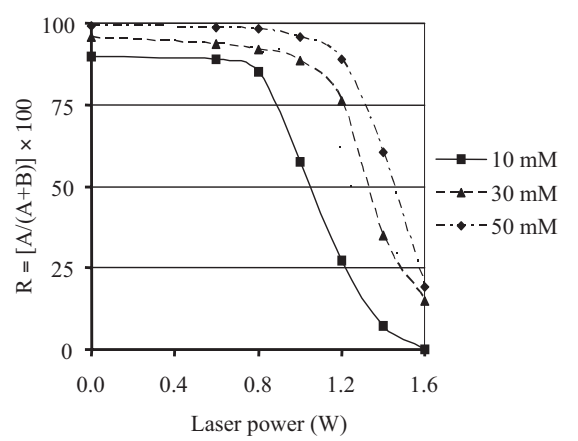

Figure 5. Plots of the percentage of complex as a function of laser power for the complexes of the c-Myb DBD with m22 (a) and MBS-I 16 (b) in $10 \mathrm{mM}, 30 \mathrm{mM}$, and $50 \mathrm{mM}$ ammonium acetate. The percentage of complex $(R)$ was calculated by the equation of $R=[A /(A+B)] \times 100$, where $A$ is the sum of the complex peak-area and B is the sum of the free c-Myb DBD peak-area, respectively. The $\mathrm{R}$ values were used for plotting the dissociation curves. 
suggest that the free c-Myb DBD is stabilized in relatively higher concentration of salt over the range of 10 to $50 \mathrm{mM}$, while a lower concentration destabilizes the protein, resulting in partial denaturation.

In our previous paper on ESI-CID experiments, significant peak broadening of the complex ion was recognized upon CID (Figure 4); thus, we used peak intensity of the most intense peak of each species to calculate the percentage of the complex. Since the charge distribution was greatly affected by the laser's irradiation power, we used total peak area for the calculation of the percentage of the complex of the c-Myb DBD and dsDNA in the present paper. The percentage of complex $(\mathrm{R})$ was calculated by the equation of $R=[A /(A+B)] \times 100$, where $A$ is the sum of the peak area of the complex and $B$ is that of the free c-Myb DBD, respectively. The $\mathrm{R}$ value and the corresponding laser power was used for plotting the dissociation curves. As mentioned above, population of the partially denatured species with higher charges seems to be large when the protein sample is prepared in the buffer with a low concentration of ammonium acetate. Since the number and total intensity of peaks for the free protein observed in the ESI mass spectrum of the complex prepared in $10 \mathrm{mM}$ ammonium acetate was larger than those of the complex prepared in $50 \mathrm{mM}$ ammonium acetate, the total peak area for the free protein in ESI mass spectra increased as the concentration of the ammonium acetate was lowered. Ionization efficiency in ESIMS was improved for the sample, especially for the complex, in $50 \mathrm{mM}$ ammonium acetate compared with that in $10 \mathrm{mM}$ ammonium acetate. As a result, the $R$ value for the sample in $50 \mathrm{mM}$ ammonium acetate was the highest among three buffer conditions for the complex of the c-Myb with wild-type 22-mer dsDNA when the laser was off, although a higher salt condition is generally disadvantageous to complex formation of a protein and DNA.

Since complete dissociation was recognized even for the complex with the highest binding affinity at $1.6 \mathrm{~W}$ laser irradiation, we selected $10 \mathrm{mM}$ ammonium acetate for further experiments.

\section{Validation of the New Method-Correlation Between $E_{50 \%}$ and Solution-Phase $\Delta \Delta G$}

To evaluate the stability of the c-Myb DBD-mutant dsDNA complexes with different solution-phase $K_{d}$ values, laser spray mass spectra of eight complexes prepared in $10 \mathrm{mM}$ ammonium acetate were acquired at various different laser powers, and the dissociation curve of each complex as a function of laser power was plotted (Figure 6). Sequences of the examined dsDNA (MBS-I 16, $\mathrm{m} 22, \mathrm{~m} 3, \mathrm{~m} 4, \mathrm{~m} 5, \mathrm{~m} 6, \mathrm{~m} 14$, and $\mathrm{m} 19$ ) are indicated in Table 1, in which solution $K_{d}$ values of the complexes with c-Myb DBD determined by filter-binding assay are also listed [13].

For accurate analysis of the solution $K_{d}$ values of the

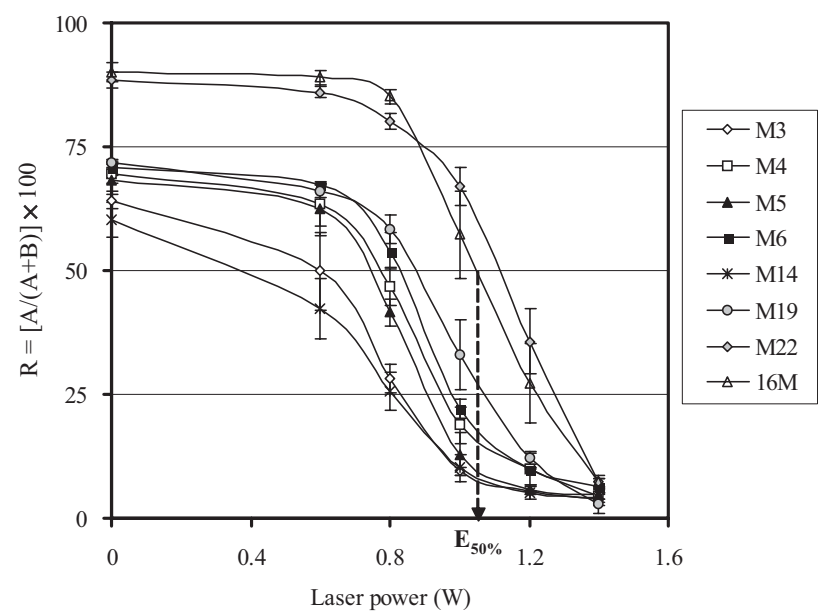

Figure 6. A plot of the percentage of complexes as a function of laser power for the complexes of the c-Myb DBD with eight dsDNA oligomers. Each dissociation curve was plotted by using the average $R$ values obtained from three independent experiments. The SD for each data point is also indicated. $\mathrm{E}_{50 \%}$ was obtained from the crossing point of the curve on $50 \%$ line of the percentage of complex $(\mathrm{R}=50)$. M3, M4 .. M22, and 16M represent the complexes of the c-Myb DBD and the corresponding 22-mer or 16-mer dsDNA (MBS-I 16) in Table 1. All the samples were prepared in $10 \mathrm{mM}$ ammonium acetate.

complex, it is preferable to carry out compensation on ionic strength, buffer composition, and solution temperature. The aim of the present study is to examine if laser spray can be an alternative method for evaluation of the binding affinity of the complexes of protein and DNA mutants. Therefore, we decided to use the $K_{d}$ values that had been determined by filter-binding assay in different buffer conditions. If the experimental conditions are kept constant, it would be possible to estimate the solution $K_{d}$ values in the buffer determined by the filter-binding assays.

To investigate the relationship between the laser power and the solution-phase $\Delta \Delta G$ of the complex, $\mathrm{E}_{50 \%}$ was determined for each complex from the dissociation curve. The value of $\mathrm{E}_{50 \%}$ stands for the laser power where $50 \%$ population of complex was dissociated. The crossing point of the dissociation curve on $50 \%$ line of the percentage of complex $(R=50)$ was employed for $\mathrm{E}_{50 \%}$ (Figure 6). Then $-\Delta \Delta G$ of each complex was plotted as a function of $E_{50 \%}$, as shown in Figure 7. The standard deviation (SD) of $\Delta \Delta G$ determined by filterbinding assay was $0.2 \mathrm{kcal} / \mathrm{mol}$ for every complex [13], and it is indicated with bars on the y-axis. Bars on the $\mathrm{x}$-axis indicate $\mathrm{SD}$ of $\mathrm{E}_{50 \%}$ obtained from three independent experiments for each complex. The correlation between $\Delta \Delta G$ values in the solution phase and $E_{50 \%}$ was examined by linear regression analysis, and the correlation factor was determined as $r=0.9808$, which was much better than the result $(r=0.859)$ obtained by ESI-CID experiments [9]. Thus, it is realized that laser spray mass spectrometry is a promising technique for readily characterizing the binding affinity of proteinmutant DNA complexes. 


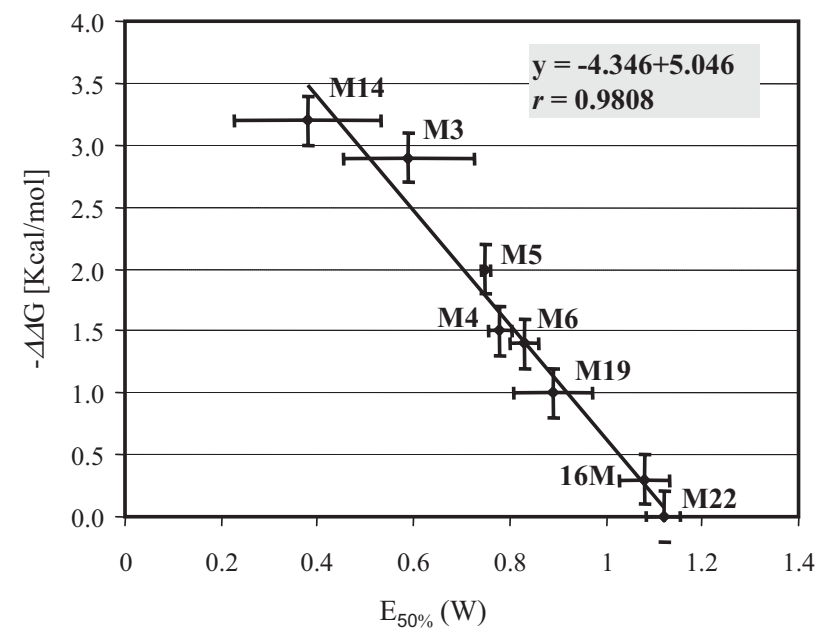

Figure 7. A plot of the solution $-\Delta \Delta G$ of complex as a function of $\mathrm{E}_{50 \%}$ for the complexes of the c-Myb DBD with eight dsDNA oligomers. The solution $\Delta \Delta G$ of each complex had been determined by filter-binding assay [13]. The SD for each $\mathrm{E}_{50 \%}$ is indicated with bars on the $x$-axis while that of each $\Delta \Delta G$ value $(0.2$ $\mathrm{kcal} / \mathrm{mol}$ ) is indicated with bars on the $\mathrm{y}$-axis.

\section{Application of Laser Spray to Analyze Five Quality Control Samples}

To identify whether laser spray can really be used to estimate the binding affinity of other protein--mutant DNA complexes, we subjected five complexes of the c-Myb DBD with singly-mutated 22-mer dsDNA (m1, $\mathrm{m} 8, \mathrm{~m} 16, \mathrm{~m} 18$, and $\mathrm{m} 20$ ) to laser spray experiments as the quality control samples. We found that a novel calibration curve has to be prepared every time to determine the binding affinity accurately because the conditions of the mass spectrometer may vary a little on different days. Laser spray is a hybrid of three basic techniques for the formation of gaseous ions from the condensed phase, i.e., energy-sudden activation by a laser, nebulization, and the action of an electric field (Figure 1). The laser tuning greatly affects the laser spray mass spectra [34]. Focusing the laser beam exactly on the center of the Taylor cone is crucial to laser spray. Once the laser beam is focused, the position of the laser beam can be maintained during a series of experiments even on different days. In contrast, the flow rate of nebulizing gas is much more critical. If a well-shaped Taylor cone is generated by controlling the nebulizing gas-flow and the laser irradiates the center of the Taylor cone, good laser spray mass spectra can be obtained. If the Taylor cone is ill-shaped, good mass spectra cannot be obtained by laser irradiation. It is quite difficult to maintain the same flow rate and condition of nebulizing gas over several days. A slight change in the flow rate of nebulizing gas greatly affects the laser spray. The $\mathrm{E}_{50 \%}$ of the same sample was found to vary when the experiments were carried out on different days.

Therefore, another calibration curve was obtained by laser spray experiments for the complexes of M3, M5, M6, M14, M19, and M22, as shown in Figure 8, which

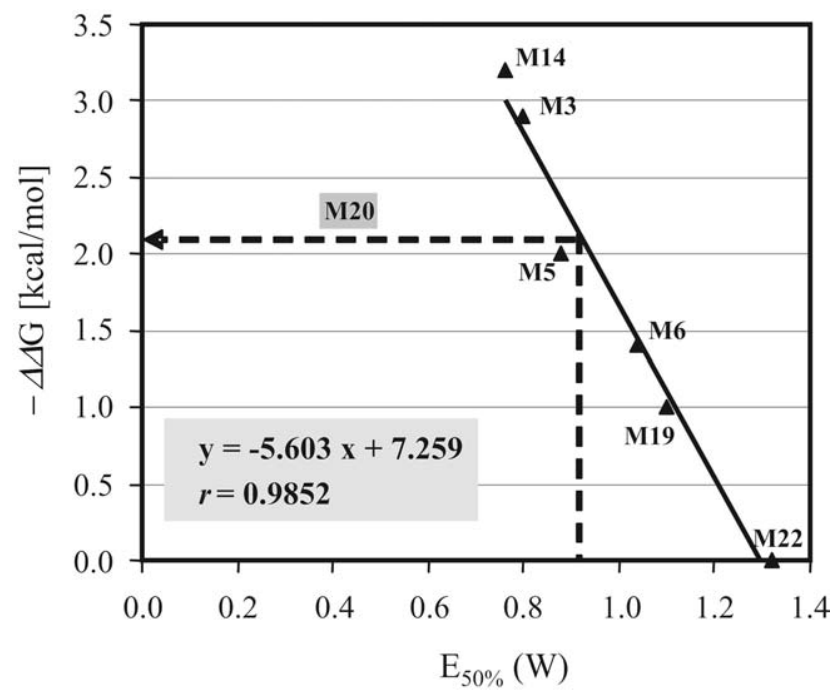

Figure 8. A calibration plot of the solution $-\Delta \Delta G$ of complex as a function of $\mathrm{E}_{50 \%}$ for six complexes of the c-Myb DBD with various dsDNA oligomers. This plot was prepared by a single laser spray experiment for each complex. The $\Delta \Delta G$ values for five other complexes of the c-Myb DBD with dsDNA of $\mathrm{m} 1, \mathrm{~m} 8, \mathrm{~m} 16$, $\mathrm{m} 18$, and $\mathrm{m} 20$ were estimated from this calibration plot by using the $\mathrm{E}_{50 \%}$ values obtained from the laser spray mass spectra. An example of the determination of $\Delta \Delta G$ value for M20, a complex of the c-Myb DBD with m20, is indicated with a broken line.

was employed for the evaluation of binding affinity of five other complexes. Linear regression analysis was carried out for the plot, and the correlation factor $(r)$ was determined from this plot. A good correlation $(r=$ 0.9852) was found between $-\Delta \Delta G$ and $E_{50 \%}$, similar to that from the plot in Figure 7. Based on the dissociation curves of five other complexes of the c-Myb DBD with mutant 22-mer dsDNA (m1, m8, m16, m18, and $\mathrm{m} 20$ ) (data not shown), we obtained the corresponding $\mathrm{E}_{50 \%}$. The $-\Delta \Delta G$ for each complex was obtained from the calibration curve (Figure 8 ) in the same manner. The results are summarized in Table 2. Relative errors of the experiments were in the range of 3.0 to $20.7 \%$ (Table 2), which confirmed that the present method is accurate enough to evaluate the binding affinity of the c-Myb DBD with some other dsDNA oligomers by laser spray.

Table 2. Results of laser spray for five quality control samples (QC samples)

\begin{tabular}{ccccc}
\hline Complex & $\begin{array}{c}-\Delta \Delta G \\
E_{5 \%}{ }^{a} \\
{[\mathrm{~W}]}\end{array}$ & $\begin{array}{c}-\Delta \Delta G[\mathrm{kcal} / \mathrm{mol}] \\
{[\mathrm{kcal} / \mathrm{mol}]} \\
\text { calculated }\end{array}$ & $\begin{array}{c}\text { from filter- } \\
\text { binding assay }\end{array}$ & $\begin{array}{c}\text { Relative } \\
\text { error }(\%)^{\mathrm{b}}\end{array}$ \\
\hline \hline M1 & 0.80 & 2.78 & 2.7 & 3.0 \\
M8 & 0.65 & 3.62 & 3.0 & 20.7 \\
M20 & 0.92 & 2.10 & 2.4 & -12.5 \\
M16 & 1.20 & 0.54 & 0.6 & -10.0 \\
M18 & 1.18 & 0.65 & 0.6 & 8.3 \\
\hline
\end{tabular}

${ }^{a}$ The value of $E_{50 \%}$ was obtained from a single laser spray experiment for each complex.

belative errors are calculated by the following equation:

Relative error $(\%)=\left[\left(-\Delta \Delta \mathrm{G}_{\text {calculated }}\right)\right.$

$\left.-\left(-\Delta \Delta \mathrm{G}_{\text {From filter-binding assay }}\right)\right] /\left(-\Delta \Delta \mathrm{G}_{\text {From filter-binding assay }}\right) \times 100$ 
It is indicated that laser spray mass spectrometry is a new and effective method for convenient characterization of protein-mutant DNA interaction. It is also promising for the analysis of the stability of other noncovalent complexes, such as protein-protein, protein-ligand, and DNA-drug in solution. The applicability of laser spray to convenient characterization of drug-DNA interaction is now undergoing investigation.

\section{Conclusions}

Investigation on the stability of thirteen complexes of the c-Myb DBD bound to 16- or 22-mer dsDNA with a single-point mutation was carried out by laser spray mass spectrometry. Protein-dsDNA complexes could easily be dissociated without any fragmentation of DNA molecules by increasing the laser power when the sample was prepared in a buffer with a low concentration of ammonium acetate. A linear correlation was found between the relative binding free-energy change $(\Delta \Delta G)$ and laser power required for the $50 \%$ dissociation $\left(\mathrm{E}_{50 \%}\right)$ by laser spray. Laser spray mass spectrometry provided much better results than ESI-CID method in evaluation of the binding affinity of protein-mutant DNA complexes. It is concluded that laser spray enables quantitative evaluation of the binding affinity of protein-mutant DNA complexes in solution under the same experimental conditions. It would also be possible to analyze the binding affinity of other noncovalent complexes, i.e., protein-protein, protein-ligand, and DNA-drug, by laser spray.

\section{Acknowledgments}

This work was supported by a Grant-in-Aid from the Japanese Ministry of Education, Science, and Culture (Special Coordination Funds for the Promotion of Science and Technology, no. 20403010).

\section{References}

1. Ganem, B.; Li, Y. T.; Henion, J. D. Detection of noncovalent receptorligand complexes by mass spectrometry. J. Am. Chem. Soc. 1991, 113, 6294-6296.

2. Daniel, J. M.; Friess, S. D.; Rajagopalan, S.; Wendt, S.; Zenobi, R. Quantitative determination of noncovalent binding interactions using soft ionization mass spectrometry. Int. J. Mass Spectrom. 2002, 216, 1-27.

3. Wendt, S.; McCombie, G.; Daniel, J.; Kienhofer, A.; Hilvert, D.; Zenobi, R. Quantitative evaluation of noncovalent chorismate mutase-inhibitor binding by ESI-MS. J. Am. Soc. Mass. Spectrom. 2003, 14, 1470-1476.

4. Yu, Y.; Kirkup, C. E.; Pi, N.; Leary, J. A. Characterization of noncovalent protein-ligand complexes and associated enzyme intermediates of GlcNAc-6-O-sulfotransferase by electrospray ionization FT-ICR mass spectrometry. J. Am. Soc. Mass Spectrom. 2004, 15, 1400-1407.

5. Heck, A. J.; Van Den. Heuvel, R. H. Investigation of intact protein complexes by mass spectrometry. Mass Spectrom. Rev. 2004, 23, 368-389.

6. Goodlett, D. R.; Ogorzalek-Loo, R. R.; Loo, J. A.; Wahl, J. H.; Udseth, H. R.; Smith, R. D. A study of the thermal denaturation of ribonuclease $\mathrm{S}$ by electrospray ionization mass spectrometry. J. Am. Soc. Mass Spectrom. 1994, 5, 614-622.

7. Gao, J.; Wu, Q.; Carbeck, J.; Lei, Q. P.; Smith, R. D.; Whitesides, G. M. Probing the energetics of dissociation of carbonic anhydrase-ligand complexes in the gas phase. Biophys. J. 1999, 76, 3253-3260.

8. Kapur, A.; Beck, J. L.; Brown, S. E.; Dixon, N. E.; Sheil, M. M. Use of electrospray ionization mass spectrometry to study binding interactions between a replication terminator protein and DNA. Protein Sci. 2002, 11, 147-157.
9. Akashi, S.; Osawa, R.; Nishimura, Y. Evaluation of protein-DNA binding affinity by electrospray ionization mass spectrometry. J. Am. Soc. Mass Spectrom. 2005, 16, 116-125.

10. Lüscher, B.; Eisenman, R. N. New light on Myc and Myb. Part II. Myb. Genes Dev. 1990, 4, 2235-2241.

11. Biedenkapp, H.; Borgmeyer, U.; Sippel, A. E.; Klempnauer, K. H. Viral $\mathrm{Myb}$ oncogene encodes a sequence-specific DNA binding activity. Nature 1988, 335, 835-837.

12. Tanikawa, J.; Yasukawa, T.; Enari, M.; Ogata, K.; Nishimura, Y.; Ishii, S.; Sarai, A. Recognition of specific DNA sequences by the c-Myb protooncogene product: Role of three repeat units in the DNA-binding domain. Proc. Natl. Acad. Sci. U.S.A. 1993, 90, 9320-9324.

13. Ogata, K.; Kanei-Ishii, C.; Sasaki, M.; Hatanaka, H.; Nagadoi, A.; Enari, M.; Nakamura, H.; Nishimura, Y.; Ishii, S.; Sarai, A. The cavity in the hydrophobic core of Myb DNA-binding domain is reserved for DNA recognition and transactivation. Nat. Struct. Biol. 1996, 3, 178-187.

14. Hiraoka, K. Laser spray: Electric field-assisted matrix-assisted laser desorption/ionization. J. Mass Spectrom. 2004, 39, 341-350.

15. Hiraoka, K.; Asakawa, Y.; Ueda, K.; Hori, A.; Sakai, T.; Okazaki, S.; Nakamura, M. Does thermal degradation occur in laser spray ionization? Rapid Commun. Mass Spectrom. 2002, 16, 1100-1105.

16. Hiraoka, K.; Asakawa, Y.; Yamamoto, Y.; Nakamura, M.; Ueda, K. High-sensitivity negative-ion laser spray for liquid chromatography/ mass spectrometry. Rapid Commun. Mass Spectrom. 2001, 15, 2020-2026.

17. Kudaka, I.; Kojima, T.; Saito, S.; Hiraoka, K. A. comparative study of laser spray and electrospray. Rapid Commun. Mass Spectrom. 2000, 14, $1558-1562$

18. Kojima, T.; Kudaka, I.; Sato, T.; Asakawa, T.; Akiyama, R.; Kawashima, Y.; Hiraoka, K. Observation of triply charged metal ion clusters by electrospray and laser spray. Rapid Commun. Mass Spectrom. 1999, 13, 2090-2097.

19. Takamizawa, A.; Itoh, Y.; Osawa, R.; Iwasaki, N.; Nishimura, Y.; Akashi, S.; Hiraoka, K. Selective dissociation of noncovalent bonds in biological molecules by laser spray. J. Mass Spectrom. 2004, 39, 10531058.

20. Loo, J. A. Studying noncovalent protein complexes by electrospray ionization mass spectrometry. Mass Spectrom. Rev. 1997, 16, 1-23.

21. Wattenberg, A.; Sobott, F.; Brutschy, B. Detection of intact hemoglobin from aqueous solution with laser desorption mass spectrometry. Rapid Commun. Mass Spectrom. 2000, 14, 859-861.

22. Brutschy, B. Studying noncovalent protein complexes in aqueous solution with laser desorption mass spectrometry. Int. J. Mass Spectrom. 2000, 203, 49-57.

23. Rockwood, A. L.; Busman, M.; Udseth, H. R.; Smith, R. D. Thermally induced dissociation of ions from electrospray mass spectrometry. Rapid Commun. Mass Spectrom. 1991, 5, 582-585.

24. Cheng, X.; Gao, Q.; Smith, R. D.; Jung, K.-E.; Switzer, C. Comparison of 3,5- and 2,5-linked DNA duplex stabilities by electrospray ionization mass spectrometry. Chem. Commun. 1996, 747-748.

25. Fändrich, M.; Tito, M. A.; Leroux, M. R.; Rostom, A. A.; Hartl, F. U.; Dobson, C. M.; Robinson, C. V. Observation of the noncovalent assembly and disassembly pathways of the chaperone complex MtGimC by mass spectrometry. Proc. Natl. Acad. Sci. U.S.A. 2000, 97, 14151-14155.

26. Benesch, J. L.; Sobott. F.; Robinson, C. V. Thermal dissociation of multimeric protein complexes by using nanoelectrospray mass spectrometry. Anal. Chem. 2003, 75, 2208-2214

27. Lim, H.-K.; Hsieh, Y. L.; Ganem, B.; Henion, J. Recognition of cell-wall peptide ligands by vancomycin group antibiotics: Studies using ion spray mass spectrometry. J. Mass Spectrom. 1995, 30, 708-714.

28. Ayed, A.; Krutchinsky, A. N.; Ens, W.; Standing, K. G.; Duckworth, H. W. Quantitative evaluation of protein-protein and ligand-protein equilibria of a large allosteric enzyme by electrospray ionization timeof-flight mass spectrometry. Rapid Commun. Mass Spectrom. 1998, 12, 339-344.

29. Jørgensen, T. J. D.; Roepstorff, P.; Heck, A. J. R. Direct determination of solution binding constants for noncovalent complexes between bacterial cell wall peptide analogues and Vancomycin group antibiotics by electrospray ionization mass spectrometry. Anal. Chem. 1998, 70, 44274432 .

30. Kempen, E. C.; Brodbelt, J. S. A Method for the determination of binding constants by electrospray ionization mass spectrometry. Anal. Chem. 2000, 72, 5411-5416.

31. Ogata, K.; Morikawa, S.; Nakamura, H.; Sekikawa, A.; Inoue, T.; Kanai, H.; Sarai, A.; Ishii, S.; Nishimura, Y. Solution structure of a specific DNA complex of the Myb DNA-binding domain with cooperative recognition helices. Cell 1994, 79, 639-648.

32. Ogata, K.; Morikawa, S.; Nakamura, H.; Hojo, H.; Yoshimura, S.; Zhang, R.; Aimoto, S.; Ametani, Y.; Hirata, Z.; Sarai, A.; Ishii, S.; Nishimura, Y. Comparison of the free and DNA complexed forms of the DNA-binding domain from c-Myb. Nat. Struct. Biol. 1995, 2, 309-320.

33. Sarai, A.; Uedaira, H.; Morii, H.; Yasukawa, T.; Ogata, K.; Nishimura, Y.; Ishii, S. Thermal stability of the DNA-binding domain of the Myb oncoprotein. Biochemistry 1993, 32, 7759-7764.

34. Takamizawa, A.; Fujimaki, S.; Sunner, J.; Hiraoka, K. Denaturation of lysozyme and myoglobin in laser spray. J. Am. Soc. Mass Spectrom. 2005, $16,860-868$.

35. Takamizawa, A.; Akashi, S.; Hiraoka, K. Comparative study of laser spray and electrospray an orthogonal TOF mass spectrometer. J. Mass Spectrom. Soc. Jpn. 2005, 53, 100-107. 